\title{
Infection risk after paediatric liver transplantation
}

\author{
Mukadder Ayşe Selimoğlư ${ }^{1 \oplus}$, Samime Kaya ${ }^{1}$, Şükrü Güngörr ${ }^{1}$, Fatma İlknur Varol ${ }^{1}$, \\ Harika Gözde Gözükara Bağ², Sezai Yılmaz ${ }^{3}$
}

Departments of ${ }^{1}$ Pediatric Gastroenterology, Hepatology, and Nutrition, ${ }^{2}$ Biostatistics and ${ }^{3}$ Liver Transplantation Institute, İnönü University Faculty of Medicine, Malatya, Turkey.

\begin{abstract}
Infections after liver transplantation (LT), despite prophylactic therapy, are still important causes of morbidity and mortality in children. Although underlying disease and immunosuppression along with the complexity of LT procedure are the major predispositions to infections, there still might be under recognised factors predisposing infections in paediatric LT. In this study, we retrospectively analysed the risk factors of bacterial, viral, and fungal infections after LT in a series of 167 children (median $=5 \mathrm{yr}$.). Of all children, $112(67 \%)$ experienced infections: 93 (55.7\%) bacterial, $56(33.5 \%)$ viral and $15(9 \%)$ fungal. Multilogistic regression analysis showed that the need of immunosuppressive switch increased total, bacterial, and viral infection risk 5.3, 2.5, and 2.5 times, respectively, $(\mathrm{p}=0.001, \mathrm{p}=0.021$, and $\mathrm{p}=0,019$, respectively). Re-LT increased bacterial infection risk 4.2 times $(\mathrm{p}=0.040)$. Viral infection risk was 10 times higher in children who had more than two re-laparotomies $(\mathrm{p}=0,002)$. Children who had post-LT, cytomegalovirus (CMV) infection had 5.6 times increased risk for fungal infection $(\mathrm{p}=0.035)$. In conclusion, infection is still an important morbidity in paediatric LT and is in close relationship with other morbidities such as surgical complications. CMV infection, itself, is an independent risk factor for fungal infection.
\end{abstract}

Key words: children, infection, liver transplantation.

Infections after liver transplantation (LT), despite prophylactic therapy, are still important causes of morbidity and mortality in children. Of patients undergoing LT, $80 \%$ experience at least one infection episode within the first year of LT, of which some result in death. ${ }^{1,2}$ Nevertheless infections are the most common cause of mortality after LT in some centres. ${ }^{3}$ Underlying disease and immunosuppression along with the complexity of LT procedure are the major predispositions to infections. ${ }^{1}$ However, there still might be under recognised factors predisposing to infections in paediatric LT.

To the best of our knowledge, there is not any paediatric study investigating the risk of all infections, bacterial, viral, and fungal, after

Mukadder Ayşe Selimoğlu

ayseselimoglu@hotmail.com

Received 22nd May 2018; accepted 14th May 2019
LT. In this study, we retrospectively analysed the risk factors of bacterial, viral, and fungal infections after LT in a series of 167 children.

\section{Material and Methods}

One hundred and sixty seven children who underwent LT for acute or chronic liver failure (ALF and CLF, respectively) between January 2011 and December 2015 at the Liver Transplantation Institute of İnönü University Faculty of Medicine were included in that study.

Medical reports and culture results were analysed retrospectively. Any sign or symptom suggesting infection including fever, hypothermia, graft dysfunction, or clinical detoriation were the indications of sampling for culture. Only culture proven bacterial infections were included. Ampicillin sulbactam is routinely used for the prophylaxis after liver transplantation and tacrolimus or cyclosporine along with corticosteroids is used 
for immunosuppression. Corticosteroids were used for only 3 months. Drug switch was made when acute rejection or adverse effects occurred. Prophylactic acyclovir was used for 3 months.

Viral serology for cytomegalovirus (CMV) and Epstein-Barr virus (EBV) was studied every three months and in case of graft dysfunction. Only PCR positive cases were analysed.

The study protocol was approval by the Institutional Ethics Committee of İnönü University (No: 2017/3-7). SPSS version 17.0 (SPSS Inc. Chicago, IL) was used for statistical analysis; student's $t$ test and Mann-Whitney-U test for the comparison of parametric and nonparametric data of two groups, respectively, and ANOVA and Kruskal Wallis tests for the comparison of more than 2 groups. Multilogistic regression analysis was used to confirm the risk factors. $p<0.05$ was considered as significant.

\section{Results}

Mean age of the children was $7.1 \pm 5.4$ years ( 5 months- 18 years; median $=5.5$ yr.). Of the children, 90 (54\%) were boys and 77 (46\%) were girls. While 79 (46.7\%) had had end stage liver disease and underwent elective LT, the remaining 88 (53.3\%) had had ALF which necessitated urgent LT. Living donor LT (LDLT) and deceased donor LT (DDLT) were performed in $118(70.7 \%)$ and 49 (29.3\%) patients, respectively. Mean intensive care stay was 15.1 \pm 23.0 (median $=8$; range $=2-173$ ) days and ward stay was $21.0 \pm 18.2$ (median $=16$; range $=0-81$ ) days. Vascular (thrombosis/stenosis) and biliary complications (leak/stenosis) developed in 36 $(21.5 \%)$ and $11(6.6 \%)$ patients, respectively; $4(2.4 \%)$ experienced both. Laparotomy and ostomy were performed in $78(46.7 \%)$ and 13 $(7.8 \%)$ patients, respectively, after LT. Fifteen patients $(9 \%)$ needed re-LT.

Of all children, 112 (67\%) experienced infections: 93 (55.7\%) bacterial, 56 (33.5) viral and 15 (9\%) fungal (all Candida spp.). The most common bacterial agents were Escherichia coli and Klebsiella spp, respectively. CMV and EBV infections were detected in $23.4 \%$ and $15.6 \%$ of children, respectively. Effects of demographic, pre- and post-LT features on the development of post-LT infections were evaluated.

\section{Demographic and pre-LT features}

Bacterial infection frequency was higher in girls compared to boys ( $65 \%$ vs. $48 \%$; $\mathrm{p}=0.026)$. Mean age and primary diagnosis distribution were not different in those with or without bacterial infection $(p>0.05)$. However, mean ages of those with or without viral infection was different (62.4 \pm 58.8 mo. vs. $97.2 \pm 64.8$ mo.; $p=0.001$ ). As a supportive finding, viral infection was more common in children younger than 2 years old $(p=0.01)$ (Fig. 1).

Mean height $\mathrm{Z}$ score was lower in those who had bacterial infection ( $\mathrm{p}=0.039 ;-1.1 \pm 1.8$ vs. -0.5 \pm 1.5 ). Children were classified as having weight $Z$ score under or above -2 SD (underweight or not) and height $Z$ score under or above -2 SD (stunted or not). Infection frequency was not different regarding underweight or stunting $(p=0.905$ and $p=0.45)$. Viral and fungal infection prevalence was higher in children with cholestatic liver disease ( $50 \%$ vs. $30 \%$; $\mathrm{p}=0.028$, and $21.9 \%$ vs. $5.9 \%$; $\mathrm{p}=0.01$, respectively).

Type of LT, LDLT or DDLT, urgent or elective, did not affect the frequency of total, bacterial or viral infection $(p>0.05)$. However, in children with DDLT, fungal infections were more common compared to LDLT $(16.5 \%$ vs. $6 \%$, $\mathrm{p}=0.041)$.

While presence of pre-LT ascites increased the risk of total and bacterial infections $(p=0.01$ and $p=0.02$, respectively), encephalopathy had no effect $(p>0.05)$. Mean Pediatric End-Stage Liver Disease/ Model for End-Stage Liver Disease (PELD/ MELD) and Child-Pugh scores were higher in children with infection (all) $(p=0.02$ and $\mathrm{p}=0.06$ ). Mean PELD/MELD score was also higher in those with viral infection $(\mathrm{p}=0.04)$.

While children with congenital heart defects had higher fungal infection prevalence $(23 \%$ vs. $5.3 \%, p=0.017$ ), presence of hepatopulmonary syndrome did not affect the frequency $(\mathrm{p}>0.05)$. 


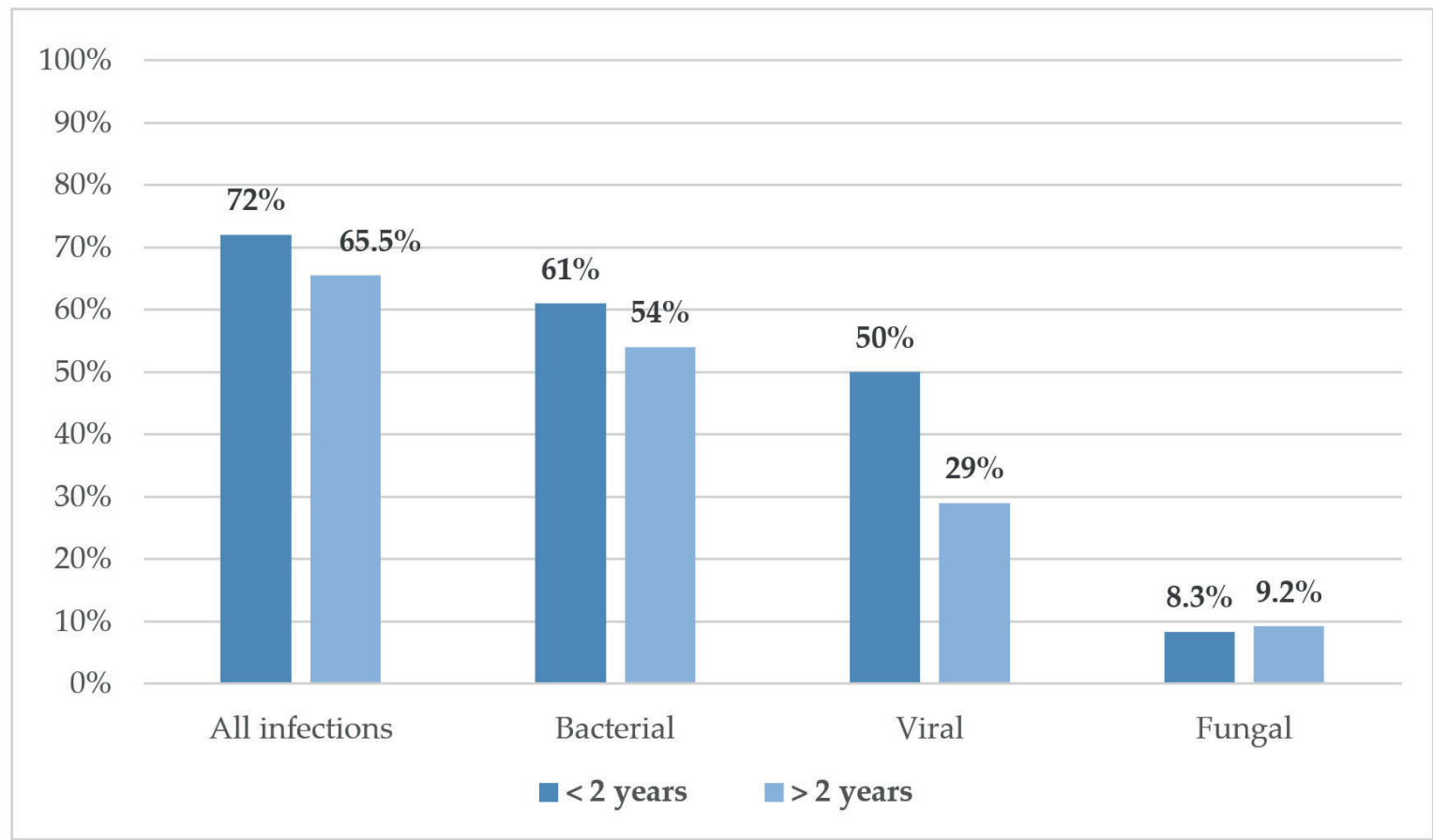

Fig. 1. Infection rates in respect with the age of the children.

Mean pre-LT hospital stay was not different in children with or without infection $(p>0.05)$. Having a positive culture result for bacteria before LT was not an indicator of post-LT infection ( $p>0.05)$. Pre-LT seropositivity for EBV or CMV did not affect post-LT viral infection prevalence $(p>0.05)$.

\section{Post-LT features}

The longer the intensive care unit (ICU) stay, the higher total infection, bacterial, viral, and fungal infection rates (Table I). Bogota bag usage was not associated with higher infection rates $(p>0.05)$. Biliary complications increased total and bacterial infection rates $(\mathrm{p}=0.02$ and $\mathrm{p}=0.01$, respectively), and intestinal perforation increased viral infection rate $(p=0.017)$. Relaparotomy was associated with higher total and viral infection rates $(\mathrm{p}=0.003$, and $\mathrm{p}=0.03$, respectively). Re-LT increased only the bacterial infection rate $(80 \%$ vs. $53.3 \%$, respectively; $\mathrm{p}=0.047$ ).

Table I. Relationship between hospital stay and infection.

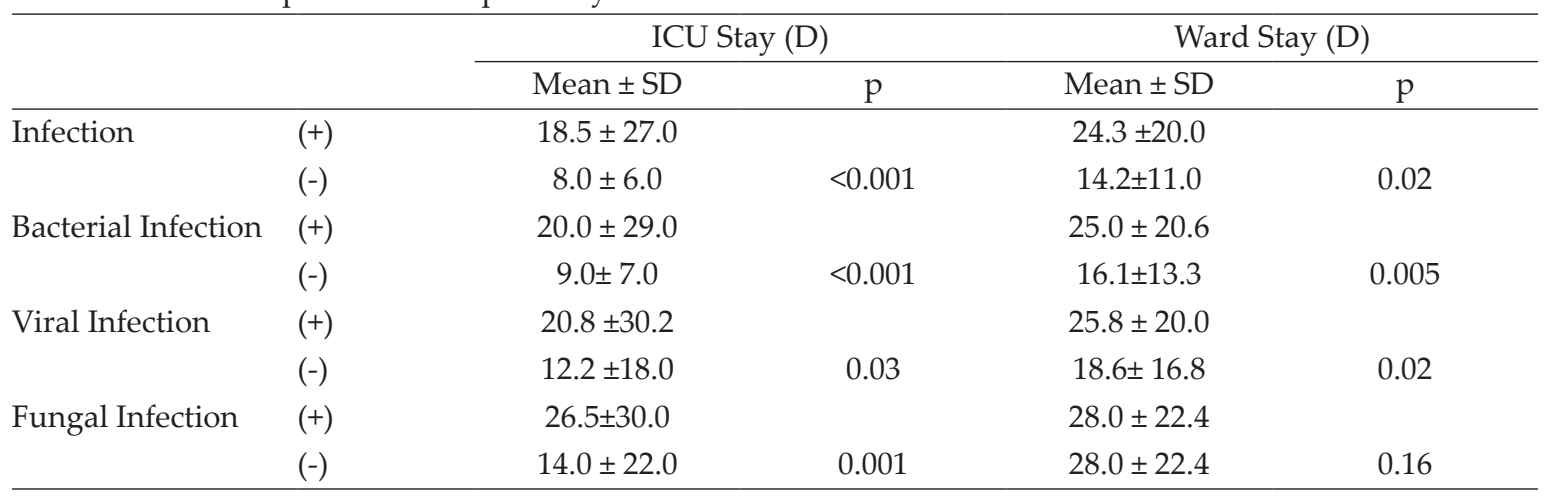

ICU: Intensive care unit 


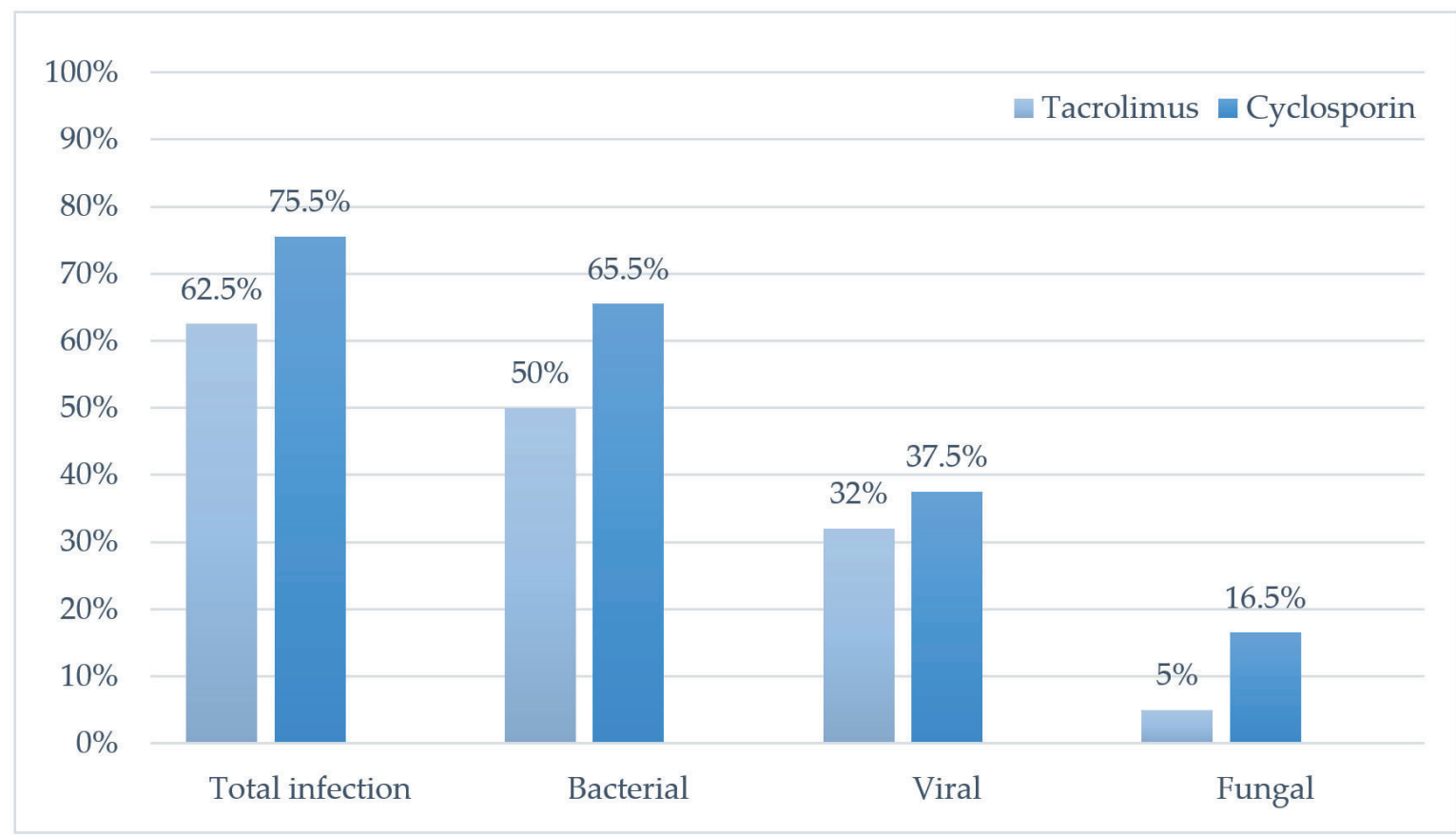

Fig. 2. Infection rates in respect with the type of immunosuppression.

Type of immunosuppressive agent did not increase the total infection, bacterial or viral infection risk ( $p>0.05)$ but fungal infection rate was higher in those on cyclosporine compared to tacrolimus $(16.5 \%$ vs. $5 \%$, p=0.01) (Fig. 2). Need for immunosuppression switch was associated with higher total, bacterial, viral, and fungal infection rates $(\mathrm{p}<0.001, \mathrm{p}=0.003, \mathrm{p}=0.002$, and $\mathrm{p}=0.03$, respectively).

It was observed that $20.5 \%$ and $5.5 \%$ of children with or without post-LT CMV, respectively, experienced fungal infection $(p=0.004)$; there was no effect on bacterial infection rate $(\mathrm{p}=0.16)$.

Data were analysed with multilogistic regression analysis and it was found that need of immunosuppressive switch had 5.3, 2.5, and 2.5 times, respectively, increased total, bacterial, and viral infection risk $(\mathrm{p}=0.001, \mathrm{p}=0.021$, and $\mathrm{p}=0,019$, respectively) (Table II). Re-LT increased bacterial infection risk 4.2 times $(\mathrm{p}=0.040)$ (Table II). Viral infection risk was 10 times higher in children who had re-laparotomy more than 2 $(p=0,002)$ (Table II). Children who had post-LT CMV infection had 5.6 times increased risk for fungal infection $(\mathrm{p}=0.035)$ (Table II).

\section{Discussion}

This study showed us that $67 \%$ of children experienced infections, most of which were bacterial (55.7\%) and viral (33.5). Pre-LT characteristics have important influences on post-LT morbidity and mortality. In this study we found mean PELD/MELD score to be higher in those who developed post-LT infection, which means that the disease severity is one of the factors predisposing to infections. In a study performed on adult patients MELD score was not found effective on infection development. ${ }^{4}$

In accordance with the findings of Avkan-Oğuz et al. ${ }^{5}$, we did not find pre-LT encephalopathy to be a risk for post-LT infection. On the other hand, re-laparotomy and biliary complications were reported as risk factors for infection ${ }^{6,7}$, like we found in our study.

When bacterial infections were evaluated, it was observed that none of the factors including primary diagnosis, disease severity, age at LT, or pre-LT hospitalization duration was responsible. While Kim et al. ${ }^{8}$ reported similar findings in 144 LT patients, in another study it 
Table II. Risk factors for post-LT infection according to logistic regression analysis.

\begin{tabular}{lccc}
\hline & OR & 95\% Confidence Interval & $\mathrm{p}$ \\
\hline $\begin{array}{l}\text { Total Infection Risk } \\
\text { Immunosuppressive Switch }\end{array}$ & 5.351 & $1.942-14.748$ & 0.001 \\
Bacterial Infection Risk & & & 0.021 \\
Immunosuppressive Switch & 2.561 & $1.150-5.703$ & 0.040 \\
Re-LT & 4.298 & $1.071-17.257$ & 0.019 \\
Viral Infection & & & 0.002 \\
Immunosuppressive Switch & 2.539 & $1.167-5.521$ & 0.035 \\
Re-Laparotomy $>2$ & 10.125 & $2.361-43.420$ & \\
Fungal Infection & & & $1.133-27.867$ \\
Post-LT CMV Infection & 5.618 & & \\
\hline
\end{tabular}

LT: Liver transplantation

CMV: Cytomegalovirus

was shown that bacteraemia risk was higher in patients with higher Child Pugh score. ${ }^{9}$ We found that total infection (bacterial, viral, and fungal) frequency was correlated with the score $(p=0.038)$.

Nafady-Hega et al. ${ }^{10}$ reported a correlation between bacterial infections and length of preLT hospital stay as opposed to the findings of our study. They observed no relationship between pre-LT ascites and bacterial infection ${ }^{10}$ but we observed that pre-LT ascites increased both total and bacterial infection frequency $(\mathrm{p}=0.01$ and $\mathrm{p}=0.02)$, though no spontaneous bacterial peritonitis was detected.

Most of the LT candidate children with chronic liver disease have malnutrition and it is accepted that malnutrition, especially chronic type, increases the complications and mortality. ${ }^{11}$ Moukarzel et al. ${ }^{12}$ showed that children having a height $\mathrm{Z}$ score under -1 were at risk of bacterial sepsis, invasive fungal infection, surgical complication, and re-LT. Likewise we found that mean height $\mathrm{Z}$ score, an indicator of chronic malnutrition, was lower in those who had bacterial infection $(p=0.039)$ but that was not the case in viral or fungal infections.

Among post-LT factors, long ICU stay increased the bacterial infection risk as expected and shown before. ${ }^{8}$ However it is not clear whether bacterial infections cause longer ICU stay or vice versa. Re-laparotomy may be one of the causes of longer ICU stay and hence higher infection rates, which was observed in our and others' studies. ${ }^{5}$ Re-laparotomy may well represent the surgical complications such as biliary leak and intestinal perforations; which were also shown to increase bacterial infections after LT. ${ }^{10,13}$ Not intestinal perforation but biliary leak was found to increase bacterial infection in our series $(p=0.01)$. Length of post-LT ward stay was also longer in those with bacterial infection.

Viral infections are also common after LT due to immunosuppression mostly during postLT 1- $6^{\text {th }}$ months and the most common viral pathogen is CMV as shown in many studies. ${ }^{14,15}$ We found that age at LT, disease severity, cholestatic nature of the disease, intestinal perforation, and the length of ICU and ward stay were effective factors for the development of viral infection. Hadley et al. ${ }^{16}$ reported the relationship between ICU stay and viral infections, as well.

Prevalence of fungal infection after LT was reported to be $5-40 \%$, mostly of Candida spp. ${ }^{17,18}$ We found the prevalence as 9\%; all Candida spp. $\mathrm{CMV}$ is a well-defined risk factor for post-LT fungal infections. ${ }^{19}$ In our study, fungal infection was detected in $20.5 \%$ and $5.5 \%$ of patients with or without CMV infection, respectively 
( $\mathrm{p}=0.004)$. We found CMV infection to be an independent risk factor which increased fungal infection risk 5.6 times ( $\mathrm{OR}=5.618, \mathrm{p}=0.035)$. Fungal infection rate was higher in DDLT compared to LDLT ( $16.5 \%$ vs. $6 \%$, $\mathrm{p}=0.03)$. This was not the case in an adult series. ${ }^{20}$

While Hadley et al. ${ }^{16}$ revealed that type of immunosuppressive used had no statistical effect on the fungal, viral, or bacterial infection rate, we found that children on cyclosporine had higher fungal infection rate $(\mathrm{p}=0,01)$.

In the final evaluation, the need of immunosuppressive switch was the independent risk factor for total, bacterial and viral infection development. Re-laparotomy and re-LT were also independent risk factors for bacterial and viral infections, respectively.

In conclusion, infection is still an important morbidity in paediatric LT and is in close relationship with other pre- and post-LT morbidities such as malnutrition, disease severity, and surgical complications. Starting before LT, strategies aiming at reducing those morbidities could lead to lower infection rates.

\section{REFERENCES}

1. Kim SI. Bacterial infection after liver transplantation. World J Gastroenterol 2014; 20: 6211-6220.

2. Watt KD, Pedersen RA, Kremers WK, Heimbach JK, Charlton MR. Evolution of causes and risk factors for mortality post-liver transplant: Results of the NIDDK long-term follow-up study. Am J Transplant 2010; 10: 1420-1427.

3. Torbenson M, Wang J, Nichols L, Jain A, Fung J, Nalesnik MA. Causes of death in autopsied liver transplantation patients. Mod Pathol 1998; 11: 37-46.

4. Juntermanns B, Manka P, Hoyer DP, et al. Infectious complications in the era of MELD. Ann Transplant 2015; 20: 297-302

5. Avkan-Oguz V, Ozkardesler S, Unek T, et al. Risk factors for early bacterial infections in liver transplantation. Transplant Proc 2013; 45: 993-997.

6. Kim SI, Kim YJ, Choi JY, et al. Strategies to reduce infectious complication using epidemiologic data analysis. Transplant Proc 2013; 45: 3061-3064.
7. Kusne S, Dummer JS, Singh N, et al. Infection after liver transplantation. An analysis of 101 consecutive cases. Medicine (Baltimore) 1988; 67: 132-143.

8. Kim SI, Kim YJ, Jun YH, et al. Epidemiology and risk factors for bacteremia in 144 consecutive livingdonor liver transplant recipients. Yonsei Med J 2009; 50: 112-121.

9. Kaido T, Mori A, Ogura Y, et al. Pre- and perioperative factors affecting infection after living donor liver transplantation. Nutrition 2012; 28: 1104-1108.

10. Nafady-Hego H, Elgendy H, Moghazy WE, Fukuda $\mathrm{K}$, Uemoto S. Pattern of bacterial and fungal infections in the first 3 months after pediatric living donor liver transplantation: an 11-year single-center experience. Liver Transpl 2011; 17: 976-984.

11. Merli M, Nicolini G, Angeloni S, Riggio O. Malnutrition is a risk factor in cirrhotic patients undergoing surgery. Nutrition 2002; 18: 978-986.

12. Moukarzel AA, Najm I, Vargas J, McDiarmid SV, Busuttil RW, Ament ME. Effect of nutritional status on outcome of orthotopic liver transplantation in pediatric patients. Transplant Proc 1990; 22: 15601563.

13. Li C, Wen TF, Mi K, Wang C, Yan LN, Li B. Analysis of infections in the first 3-month after living donor liver transplantation. World J Gastroenterol 2012; 18: 1975-1980.

14. Gane E, Saliba F, Valdecasas GJ, et al. Randomised trial of efficacy and safety of oral ganciclovir in the prevention of cytomegalovirus disease in livertransplant recipients. Lancet 1997; 350: 1729-1733.

15. Paya C, Humar A, Dominguez E, et al; Valganciclovir Solid Organ Transplant Study Group. Efficacy and safety of valganciclovir vs. oral ganciclovir for prevention of cytomegalovirus disease in solid organ transplant recipients. Am J Transplant 2004; 4: 611-620.

16. Hadley S, Samore MH, Lewis WD, Jenkins RL, Karchmer AW, Hammer SM. Major infectious complications after orthotopic liver transplantation and comparison of outcomes in patients receiving cyclosporine or FK506 as primary immunosuppression. Transplantation 1995; 59: 851859.

17. Singh N. Fungal infections in the recipients of solid organ transplantation. Infect Dis Clin North Am 2003; 17: 113-134.

18. Singh N, Wagener MM, Marino IR, Gayowski $\mathrm{T}$. Trends in invasive fungal infections in liver transplant recipients: Correlation with evolution in transplantation practices. Transplantation 2002; 73: 63-67. 
19. George MJ, Snydman DR, Werner BG, et al; Boston Center for Liver Transplantation CMVIG-Study Group.The independent role of cytomegalovirus as a risk factor for invasive fungal disease in orthotopic liver transplant recipients. Am J Med 1997; 103: 106113
20. Saner FH, Olde Damink SW, Pavlakovic G, et al. Pulmonary and blood stream infections in adult living donor and cadaveric liver transplant patients. Transplantation 2008; 85: 1564-1568. 